\title{
UTILIZAÇÃO DE BIOADSORVENTES TRATAMENTO DE EFLUENTES INDUSTRIAIS.
}

\author{
A. J. P. ARAUJO ${ }^{1}$, S.M. S. MARIZ1 ${ }^{1}$, V. L. MOCHIZUKI ${ }^{1}$, K. S. M. G. SOUZA ${ }^{1}$, G. Z. \\ CLERICUZI $^{1}$ \\ ${ }^{1}$ Universidade Federal da Paraíba, Departamento de Engenharia Química \\ E-mail para contato: angeolino_pontes@hotmail.com, sillasmatheus2010@hotmail.com, \\ karlasilvana@gmail.com, clericuzi.zc@gmail.com
}

\begin{abstract}
RESUMO - Bioadsorventes podem ser utilizados para minimizar danos ambientais decorrentes dos descartes de efluentes da indústria petroquímica. O presente trabalho avaliou o percentual de remoção do teor de óleo em efluentes sintéticos, a partir da biomassa de uma fibra natural, Sisal (Agave sisalana), e do exoesqueleto do caranguejo Guajá (Calappa ocellata), ambos utilizados em sua forma in natura. Os ensaios foram realizados através de um planejamento experimental $2^{3}$ com três pontos centrais, utilizando efluentes sintéticos em 5 horas de contato. As biomassas utilizadas foram caracterizadas através da análise granulométrica e da difração de raios X (DRX). A fibra vegetal obteve percentual de remoção de aproximadamente $90 \%$ e o crustáceo de $70 \%$. O estudo sobre o equilíbrio entre os bioadsorventes e o adsorbato foi realizado e o modelo de Langmuir se ajustou melhor para os dois bioadsorventes. De acordo com o estudo desenvolvido os dois bioadsorventes apresentam eficiência na remoção do teor de óleo em efluentes sintéticos, sendo uma alternativa por também apresentar viabilidade econômica.
\end{abstract}

\section{INTRODUÇÃO}

Descarte de efluentes das indústrias petroquímicas constitui uma grande preocupação em todos os países do mundo. Este descarte não só representa perda de óleo, como também um impacto negativo ao meio ambiente. A poluição das águas por óleos representa um percentual elevado nos problemas por contaminantes orgânicos uma vez que os combustíveis fósseis, como o petróleo e seus subprodutos, prejudicam a aeração e a iluminação natural de cursos d'água, devido à formação de um filme insolúvel na superfície, produzindo efeitos nocivos na fauna e flora. Além disso, o derrame de poucos gramas de óleo acarreta na inutilização de dezenas, ou até centenas, de metros cúbicos de água para consumo humano (Rosa e Rubio, 2003; Corseuil e Marins, 1997). Métodos de tratamento desses efluentes visam diminuir os impactos gerados no meio ambiente e atender as exigências ambientais estabelecidas nas resoluções $n^{\circ}$ 393, 397 e 430 do Conselho Nacional do Meio Ambiente CONAMA.

O objetivo do presente trabalho é analisar a potencialidade, a partir da biomassa in natura, de uma fibra natural, Sisal (Agave sisalana), e do exoesqueleto do Caranguejo Guajá (Calappa ocellata), empregados na redução do teor de óleo em águas de efluentes sintéticos. 
O caranguejo Guajá, possui em sua composição a quitina, biopolímero com alta cadeia molecular, que tem a estrutura química similar a celulose, presente na fibra vegetal do Sisal.

\section{METODOLOGIA}

\subsection{Caracterização dos Bioadsorventes}

O Sisal foi previamente moído em um moinho de facas e o exoesqueleto do caranguejo Guajá em um moinho de discos. Foram realizados ensaios de peneiramento e a fração retida do Sisal e do caranguejo Guajá foram, respectivamente, 30 e 150 mesh. Foi realizado, também, o ensaio de difração de raios X (DRX) para caracterização das biomassas.

\subsection{Ensaios de Banho Finito}

Foram preparadas emulsões óleo/água/cloreto de sódio (solução sintética), sendo fixa a concentração de $5 \mathrm{~g} / \mathrm{L}$ para o cloreto de sódio. A fase oleosa da emulsão é composta por óleos minerais derivados de petróleo e aditivos

Os ensaios de adsorção em banho finito foram realizados variando a concentração de óleo, pH e temperatura. A primeira etapa constituiu-se do planejamento experimental, posteriormente foram realizados os ensaios para obtenção das isotermas de adsorção. Os ensaios foram preparados adicionando $1 \mathrm{~g}$ do bioadsorvente aos erlenmeyers e $50 \mathrm{~mL}$ do efluente sintético. Em seguida, foi realizado o controle de $\mathrm{pH}$, na temperatura determinada. Para correção do $\mathrm{pH}$ foi utilizado soluções diluídas de hidróxido de sódio e ácido nítrico. Os erlenmeyers foram levados para agitação mecânica durante 5 horas, sob uma rotação de 234 rpm. Após a agitação mecânica as amostras ficaram em repouso por, aproximadamente, $36 \mathrm{~h}$ para posterior leitura.

\subsection{Planejamento Experimental}

Os experimentos foram preparados conforme o planejamento experimental apresentado na Tabela 1.

Tabela 1- Planejamento experimental $2^{3}$ com 3 pontos centrais

\begin{tabular}{cccc}
\hline Ensaio & $\mathbf{p H}$ & Temperatura $\left({ }^{\mathbf{0}} \mathbf{C}\right)$ & Conc. de óleo $(\mathbf{m g} / \mathbf{L})$ \\
\hline 1 & 3 & 28 & 300 \\
\hline 2 & 7 & 28 & 300 \\
\hline 3 & 3 & 40 & 300 \\
\hline 4 & 7 & 40 & 300 \\
\hline 5 & 3 & 28 & 500 \\
\hline 6 & 7 & 28 & 500 \\
\hline 7 & 3 & 40 & 500 \\
\hline 8 & 7 & 40 & 500 \\
\hline 9 & 5 & 34 & 400 \\
\hline 10 & 5 & 34 & 400 \\
\hline 11 & 5 & 34 & 400 \\
\hline
\end{tabular}




\subsection{Determinação do Percentual de Óleo Removido e Capacidade de Adsorção}

Método do clorofórmio: utilizou-se o clorofórmio como solvente para o sobrenadante das amostras. Foi pipetado $5 \mathrm{ml}$ de ambos e adicionados em um tubo de ensaio. Agitou-se, por aproximadamente 1 minuto, em agitador de tubos, e esperou-se a separação de fases. $\mathrm{O}$ solvente foi coletado e através da análise de absorbância, utilizando o espectrofotômetro de UV-Visível, no comprimento de onda de $262 \mathrm{~nm}$, foi determinado o percentual de óleo removido.

Percentual de remoção e capacidade de adsorção no equilíbrio: o percentual de remoção de óleo em efluentes sintéticos foi determinado através da Equação 1, e a capacidade de adsorção no equilíbrio através da Equação 2.

$$
\% \operatorname{Re} m=\left(\frac{C_{o}-C}{C_{o}}\right) * 100
$$

Onde: $\mathrm{C}_{0}$ : concentração inicial da solução $(\mathrm{mg} / \mathrm{L}) ; \mathrm{C}$ : concentração final da solução $(\mathrm{mg} / \mathrm{L})$.

$$
q_{e q}=\frac{V}{m}\left(C_{o}-C_{e q}\right)
$$

Onde: V: volume do efluente sintético (L); m: massa do bioadsorvente (g); $\mathrm{C}_{\mathrm{eq}}$ : concentração de equilíbrio $(\mathrm{mg} / \mathrm{L})$.

Com estes valores utilizou-se o software Statistica para observar os efeitos, Anova, gráficos de superfície e o de Pareto.

\subsection{Isotermas de Adsorção}

Existem vários modelos que descrevem as isotermas de adsorção no sentido de desenvolver expressões matemáticas que representem a relação da capacidade de adsorção e a concentração do adsorbato na solução. Essas isotermas são desenvolvidas a partir de mecanismos propostos de adsorção e dentre estes modelos os mais conhecidos são o modelo de Langmuir e de Freundlich (Paulino et al., 2007).

Os ensaios foram realizados simultaneamente para cada bioadsorvente, colocando-se $50 \mathrm{ml}$ de efluente sintético, com concentrações de 10, 20, 50, 100, 200, 300, 400, 500, 600 e $700 \mathrm{mg} / \mathrm{L}$ de óleo em água, com pH e temperatura, controlados. As condições de $\mathrm{pH}$ e temperatura foram obtidas a partir do tratamento de dados, no software Statistica, do planejamento experimental. $\mathrm{O}$ procedimento experimental para a realização dos ensaios das isotermas de equilíbrio é o mesmo descrito na seção 2.2.. 


\section{RESULTADOS E DISCUSSÃO}

\subsection{Caracterização dos Bioadsorventes}

O resultado para a análise de DRX do pó do exoesqueleto do caranguejo Guajá mostra a presença de material cristalino caracterizado por vários picos estreitos e intensos, conforme mostrado na Figura 1a. O difratograma do pó da fibra de Sisal, mostrado na Figura 1b apresenta picos que representam os planos de cristal característicos dos materiais lignocelulosicos.

Figura 1 - DRX do (a) Caranguejo Guajá e (b) Sisal.

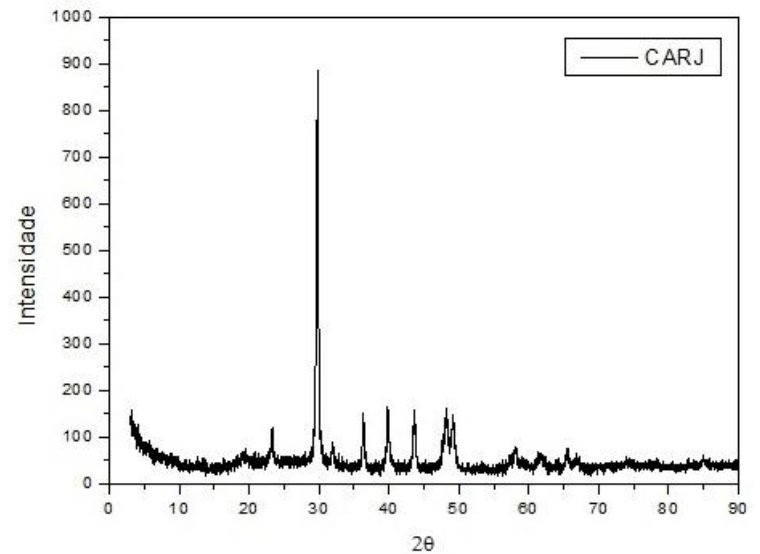

a)

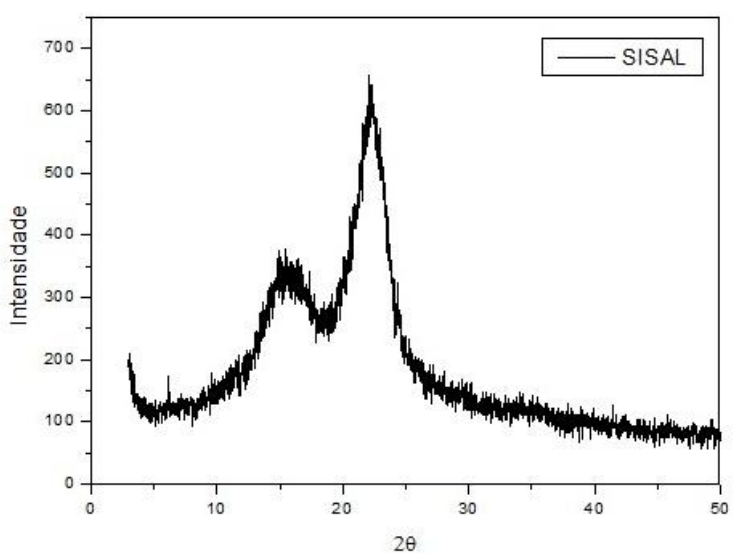

b)

Na Figura 1a o material cristalino foi atribuído a compostos inorgânicos, como derivados de cálcio, comuns em carapaças de crustáceos. Ainda é possível observar duas reflexões no início do difratograma, sendo uma característica de material amorfo, provavelmente pelo fato de se tratar de um biopolímero com alta cadeia molecular e estarem desorganizadas.

Na Figura 1b é possível observar a presença da lignina e celulose nos dois picos presentes. A lignina são macromoléculas amorfas e a celulose, biopolímero de cadeia longa, são moléculas distribuídas aleatoriamente.

\subsection{Avaliação da Remoção de Óleo em Efluente Sintético}

Os resultados obtidos para o percentual de remoção de óleo em efluente sintético utilizando o exoesqueleto do caranguejo Guajá e a fibra do Sisal, como bioadsorventes, estão apresentados na Tabela 2 e foram calculados através da Equação 1. 
Tabela 2 - Resultados obtidos para remoção de óleo em efluente sintético.

\begin{tabular}{cccccc}
\hline \multicolumn{3}{c}{ Caranguejo Guajá } & \multicolumn{3}{c}{ Sisal } \\
\hline Ensaio & $\mathrm{C}_{0}(\mathrm{mg} / \mathrm{L})$ & $\%$ Rem. & Ensaio & $\mathrm{C}_{0}(\mathrm{mg} / \mathrm{L})$ & $\%$ Rem. \\
\hline 1 & 299,4 & 42,27963 & 1 & 299,4 & 69,63223 \\
\hline 2 & 299,4 & 41,53534 & 2 & 299,4 & 71,67902 \\
\hline 3 & 299,4 & 44,88464 & 3 & 299,4 & 68,32973 \\
\hline 4 & 299,4 & 44,14035 & 4 & 299,4 & 78,74977 \\
\hline 5 & 511,8 & 66,66932 & 5 & 511,8 & 85,93597 \\
\hline 6 & 511,8 & 61,77102 & 6 & 511,8 & 85,71827 \\
\hline $\mathbf{7}$ & $\mathbf{5 1 1 , 2}$ & $\mathbf{6 9 , 8 9 9 5 7}$ & 7 & 511,2 & 88,31700 \\
\hline 8 & 511,2 & 68,26489 & $\mathbf{8}$ & $\mathbf{5 1 1 , 2}$ & $\mathbf{8 9 , 9 5 1 6 8}$ \\
\hline 9 & 419 & 62,61124 & 9 & 419 & 89,33609 \\
\hline 10 & 419 & 64,47267 & 10 & 419 & 88,93721 \\
\hline 11 & 419 & 62,87716 & 11 & 419 & 88,00649 \\
\hline
\end{tabular}

Com os resultados obtidos, utilizou-se o software Statistica para observar os efeitos, Anova, gráficos de superfície e de pareto. Através dos resultados obtidos verificou-se que para o caranguejo Guajá o experimento 7 foi viável estatisticamente, já para o Sisal foi o experimento 8 .

\subsection{Estudo de Isotermas de Adsorção}

As quantidades adsorvidas foram calculadas através da Equação 2. As isotermas de adsorção descrevem como o soluto interage com o adsorvente. Foram testados dois modelos, Langmuir e Freundlich, em suas formas lineares (Equação 3 e Equação 4, respectivamente) e utilizando o método de regressão linear com o auxílio do software Microsoft Excel (2016).

$$
\begin{aligned}
& \frac{C_{e}}{Q_{e}}=\frac{1}{K_{L}}+\frac{a_{L}}{K_{L}} C_{e} \\
& \log Q_{e}=\log K_{F}+\frac{1}{n} \log C_{e}
\end{aligned}
$$

Onde: Qe: quantidade adsorvida (mg/g); Ce: concentração final do soluto (mg/L); $\mathrm{K}_{\mathrm{L}}$ e $a_{L}$ : são as constantes isotérmicas de Langmuir; $K_{F}$ : constante de Freundlich; 1/n: expoente da equação de Freundlich.

Os coeficientes de correlação $\left(\mathrm{R}^{2}\right)$ obtidos se ajustaram melhor para o modelo Langmuir, para ambos bioadsorventes, a seguir temos as isotermas de adsorção representadas na Figura 2. 
Figura 2 - Isotermas de adsorção: (a) caranguejo Guajá e (b) Sisal.
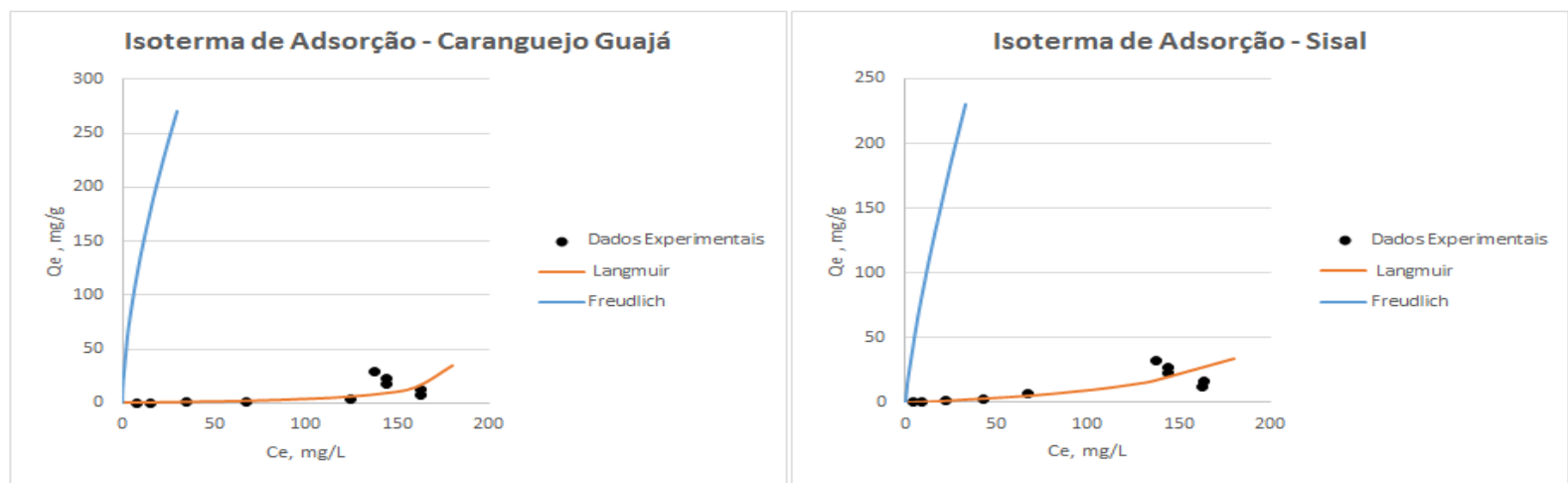

a)

b)

De acordo com Figura 2 o modelo de Langmuir se ajustou melhor aos resultados experimentais do que o modelo de Freundlich.

\section{CONCLUSÃO}

Os resultados obtidos demonstram que tanto o pó do exoesqueleto do caranguejo Guajá, como o Sisal tem considerável potencial na remoção de óleo em efluentes sintéticos na sua forma in natura. O maior percentual de remoção de óleo ocorreu na maior concentração de óleo em água e maior temperatura para ambos os bioadsorventes, já para o $\mathrm{pH}$ essa remoção é otimizada para o maior valor para a fibra vegetal e o menor valor para o crustáceo.

A isoterma de Langmuir representa os dados experimentais para ambos os bioadsorventes utilizados. A biomassa utilizada para remoção de óleo em efluentes sintéticos oferece às indústrias petroquímicas uma nova opção para o tratamento de seus efluentes industriais. Estes materiais existem em abundância no Brasil, possuem um baixo custo, além de serem biodegradáveis e não oferecerem risco de contaminação ao meio ambiente.

\section{REFERÊNCIAS}

CORESUIL, H. X.; MARINS, M. D. Contaminação de águas subterrâneas por derramamentos de gasolina: O problema é grave? Engenharia Sanitária e Ambiental, v.2., n.2, p.50-54, 1997.

MINISTÉRIO DO MEIO AMBIENTE. Conselho Nacional do Meio Ambiente - CONAMA. Resolução $n^{\circ}$ 393, de 8 de agosto de 2007. Resolução n ${ }^{\circ} 397$, de 3 de abril de 2008. Resolução n ${ }^{\circ}$ 430, de 13 de Maio de 2011.

PAULINO, Alexandre T.; GUILHERME, Marcos R.; REIS, Adriano V.; TAMBOURGI, Elias B.; NOZAKI, Jorge; MUNIZ, Edvani, C. Capacity of adsorption of $\mathrm{Pb}^{2+}$ and $\mathrm{Ni}^{2+}$ from aqueous solutions by chitosan produced from silkworm chrysalides in different degrees of deacetylation. Journal of Hazardous Materials, v. 147, p. 139 -147, 2007.

ROSA, J. J.; RUBIO, J. Desenvolvimento de um novo processo de tratamento de águas oleosas - Processo FF. In: XIX Prêmio Jovem Cientista - 2003 - Água - Fonte da Vida. 